\title{
A STRESS-WAVE GENERATOR FOR SNOW AND IGE STUDIES
}

\author{
By D. Bowles \\ (Water Resources Research Institute, University of Wyoming, Laramie, Wyoming 82070, \\ U.S.A.) \\ and R. L. BRown \\ (Department of Civil Engineering and Engineering Mechanics, Montana State University, \\ Bozeman, Montana 5971 7, U.S.A.)
}

\begin{abstract}
An electromagnetic stress-wave generator which was developed to study shock waves in snow and ice is described. This system works on the principle of generating large electrical currents to produce highly transient loads on the test specimen. In its present configuration, the generator can produce pressures ranging from a few kilopascals to as large as $\mathrm{rO}^{4} \mathrm{kPa}$ and load frequencies as, high as $\mathrm{r}_{50} \mathrm{kHz}$. The system has been found to have high repeatability and has good turn-round time.

RÉsumé. Un générateur d'ondes de pression pour les études sur la neige et la glace. On décrit un générateur électrique d'ondes de contraintes mis au point pour étudier les ondes de choc dans la neige et la glace. Le système repose sur le principe de la création de forts courants électriques pour produire de fortes poussées passagères sur l'échantillon de contrôle. Dans sa configuration présente, le générateur peut produire des pressions allant de quelques $\mathrm{kPa}$ jusqu'à $10^{4} \mathrm{kPa}$ à des fréquences atteignant $150 \mathrm{kHz}$. On a reconnu au système une forte répétitivité et une bonne durée de service.

Zusammenfassung. Ein Druckwellen-Generator für Schnee und Eisstudien. Es wird ein elektromagnetischer Druckwellen-Generator beschrieben, der zum Studium von Schockwellen in Schnee und Eis entwickelt wurde. Das System arbeitet nach dem Prinzip der Erzeugung grosser elektrischer Ströme zur Aufbringung hochtransienter Belastungen auf die Testprobe. In seiner gegenwärtigen Ausführung kann der Generator Drucke im Bereich von wenigen $\mathrm{kPa}$ bis $\mathrm{zu} 10^{4} \mathrm{kPa}$ und Luftfrequenzen bis zu ${ }_{150} \mathrm{kHz}$ erzeugen. Das System erwies seine hohe Reproduktionsfähigkeit und seine Eignung für Dauerbetrieb.
\end{abstract}

\section{INTRODUGTION}

Other than the pioneering work by Napadensky ( 1964 ), there has been very little significant laboratory work on plastic shock waves in snow. Other work includes studies on shock waves in wet snow by Wakahama and Satō (1977). Brown (1979[a], [b], [c]) has made theoretical studies of steady and non-steady waves in snow, and the results appear reasonable when compared to what little experimental evidence is available for stress waves.

In order to improve on the quantity and quality of shock-wave data, an electromagnetic stress-wave generator has been constructed, and this instrument is described in detail here. Other methods of generating shock waves could have been used. For instance, explosives can be used to produce a wide range of wave amplitudes, although wave frequency is not an easily controlled parameter, and explosives also usually have a great deal of experimental scatter. The electromagnetic generator was chosen, since it appeared to provide an optimum combination of pressure and frequency capability. In addition it has negligible experimental scatter and is easy to use. One drawback is the danger associated with high voltages, and such a system must have incorporated into it safety features to minimize this aspect of the system. However the use of explosives also requires implementation of safety features.

\section{DESGRIPTION OF STRESS-WAVE GENERATOR}

Figure I shows the assembled system, and Figure 2 illustrates the circuitry. Basically, the electromagnetic generator consists of a $20 \mathrm{kV}$ capacitor with a capacitance of $30 \mu \mathrm{F}$, a triggering unit, a spark-gap trigger, and a system of conducting plates and load strips. The generator works on the principle that when two high-energy electric currents are conducted in opposite directions along adjacent parallel strips, a strong repulsive electromagnetic force is generated to force the two strips apart. 


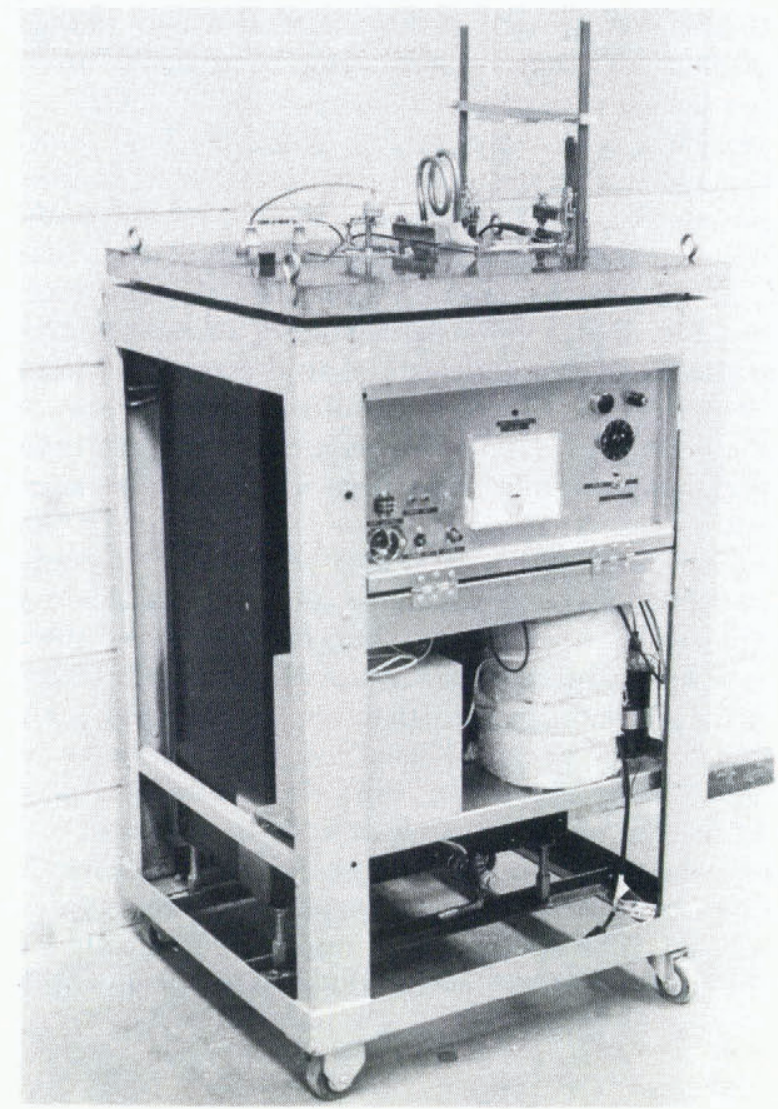

Fig. I. Assembled electromagnetic stress-wave generator.

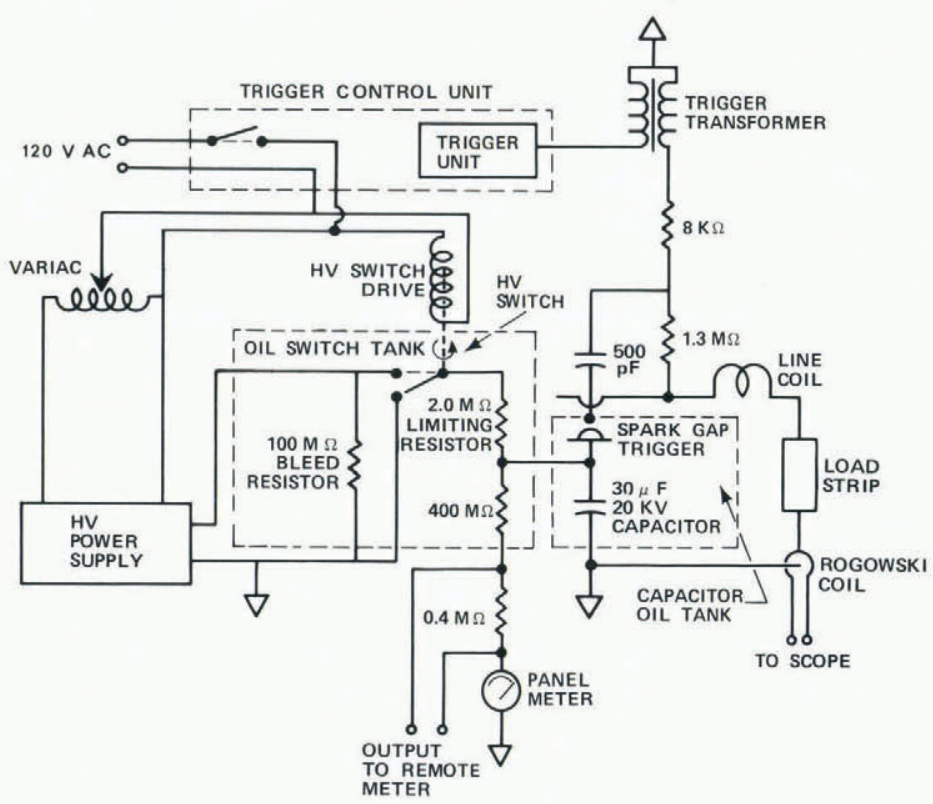

Fig. 2. Schematic diagram of circuitry for stress-wave generator. 
The capacitor and high-voltage side of the trigger are both completely submerged in a tank filled with transformer oil, thereby insulating components and reducing any corona effects that might occur during charging of the capacitor. A $20 \mathrm{kV}$ regulated power supply is used to charge the capacitor, and charging time generally is less than $5 \mathrm{~min}$. The capacitor voltage can be read from either a gauge on the instrument panel or from a digital voltmeter if more accuracy is required. A $400 \mathrm{M} \Omega$ dropping resistor is used to drop the voltage to the gauge. The digital voltmeter is connected to opposite ends of a $0.4 \mathrm{M} \Omega$ resistor in series with the dropping resistor, so that a I V output on the digital meter corresponds to a I ooo V charge in the capacitor. The digital voltmeter is connected remotely to the generator, so that charge voltage can be monitored from outside the cold room in which the testing is done.

As can be seen in Figure 2, the electrical circuitry consists of three separate components: (I) the trigger control system; (2) the power supply, capacitor, and conducting elements; and (3) the monitoring instruments. While these three separate systems are interconnected, they serve different purposes.

The trigger control unit outlined in Figure 2 serves several purposes. First it controls power to the entire system. Second, when the power is switched on, an electromagnet activates a high-voltage switch to close the charging circuit to allow the capacitor to be charged. If the system is turned off or a power failure occurs, the switch automatically opens to allow a limiting resistor to discharge the capacitor. In addition, a $100 \mathrm{M} \Omega$ bleed resistor is also permanently installed in the circuit to bleed the capacitor down in case the H.V. switch for the other resistor should fail. The control unit also controls the power to the high-voltage power supply and contains the trigger module which, by means of a transformer, pulses the spark gap with a $25 \mathrm{kV}$ pulse. This ionizes the gases in the trigger which closes the circuit and allows the current to be conducted across the spark gap, through a control coil to the load strip and to the ground side. The coil is used to make the inductance of the complete system large enough so that the current will not exceed the maximum allowable current for the spark gap.

\section{ELEGTROMAGNETIC THEORY}

The generator is a $L R C$ circuit, and the system performance is determined by the differential equation

$$
\frac{\mathrm{d}^{2}}{\mathrm{~d} t^{2}}(L Q)+R \frac{\mathrm{d} Q}{\mathrm{~d} t}+\frac{Q}{C}=0
$$

where $Q$ is the instantaneous capacitor charge, $L$ is the circuit inductance, $R$ is the total circuit resistance, and $C$ is the capacitance. In the underdamped mode, the solution to Equation ( $\mathrm{I}$ ) is

$$
Q(t)=\left[Q_{0} \exp (-a t)\right]\left[\frac{a}{\omega} \sin \omega t+\cos \omega t\right]
$$

where

$$
\begin{aligned}
a & =R / 2 L, \\
\omega & =\mathrm{I} / L C-(R / 2 L)^{2} .
\end{aligned}
$$

The instantaneous current $i(t)$ can be shown to be

$$
i(t)=\frac{Q_{0}}{\omega L C} \exp (-a t) \sin \omega t .
$$

The current is exponentially damped, and if $T$ is the period of the oscillating current, the full-cycle peak-to-peak ratio of the current amplitude is

$$
\frac{A_{3}}{A_{\mathrm{I}}}=\exp (-a T)
$$


where $A_{\mathrm{I}}$ and $A_{3}$ are the peak current values of two successive complete cycles. The values of $L$ and $C$ may then be solved for in terms of $C, T$, and $A_{3} / A_{\mathrm{I}}$. This yields (Snell and others, 1973)

$$
\begin{aligned}
& R=\frac{-2 T \ln \left(A_{3} / A_{\mathrm{I}}\right)}{C\left[(2 \pi)^{2}+\left(\ln \left(A_{3} / A_{\mathrm{I}}\right)\right)^{2}\right]}, \\
& L=\frac{T^{2}}{C\left[(2 \pi)^{2}+\left(\ln \left(A_{3} / A_{\mathrm{I}}\right)\right)^{2}\right]} .
\end{aligned}
$$

The pressure $p$ produced between the two conducting strips varies with the current as

$$
p=\frac{\mu}{2}\left(\frac{i}{w}\right)^{2}
$$

where $w$ is the strip width, and $\mu$ is the magnetic permeability of the material separating the strips, which, in this case is $0.254 \mathrm{~mm}$ thick Mylar. Equation (9) is valid so long as the strip width $w$ is large compared to the separation of the conducting plates.

\section{AsSESSMENT OF GENERATOR PERFormance}

In its present form, the generator has about $6000 \mathrm{~J}$ of energy when charged to $20 \mathrm{kV}$. Maximum current with this configuration is about $160 \mathrm{kA}$. The spark gap, however, is designed for a maximum current of about $100 \mathrm{kA}$, so the maximum voltage used to date is about $15 \mathrm{kV}$. This level of current and voltage was however found to be sufficient to produce high-pressure shock waves in snow.

When the system was originally completed and first tested, the resistance and inductance were found to be $3.75 \mathrm{~m} \Omega$ and $85 \mathrm{nH}$, respectively, and a capacitor voltage of ${ }_{5} \mathrm{kV}$ resulted in currents of about $275 \mathrm{kA}$, which, after about 20 shots, destroyed the spark gap. After that, the control coil shown in Figures I and 2 was placed in series between the capacitor and load strips to raise $L$ and $R$ to values of $650 \mathrm{nH}$ and $19 \mathrm{~m} \Omega$, which keeps the maximum current below roo kA when the capacitor voltage is less than $15 \mathrm{kV}$. This is significantly lower than the potential system output $(450 \mathrm{kA}$ at $20 \mathrm{kV})$ when the control coil is removed, but to date a spark gap to handle these current levels has not been constructed for the stress-wave generator.

The current in the circuit is monitored by a Rogowski coil that is encircled by the conducting strips near the end of the load strips, as can be seen in Figure 2. This coil is simply a length of insulated wire that is looped and twisted tightly into a shorter length. When this is placed adjacent to the conducting strip (in this case, at a point near the load strip), the electromagnetic field set up by the large current produces a voltage across the leads to the Rogowski coil. Actually it makes little difference if the coil encircles the strip as indicated in Figure 2 or is encircled by the strip itself, as was done in our case. The electromagnetic field produces a voltage across the coil leads in either case. The voltage across the leads from the Rogowski coil (Snell and others, 1973) is proportional to the instantaneous voltage in the capacitor. The output from a typical oscilloscope trace of the coil output is shown in Figure 3 . Snell and others (1973) have shown that the maximum current can be determined from the period $T$ of the Rogowski output and the full-cycle peak-to-peak ratio $A_{3} / A_{I}$ of the voltage generated across the coil. This relation is

$$
I_{\max }=V_{0} C\left(\frac{2 \pi}{T}\right)\left(\frac{A_{3}}{A_{1}}\right)^{\frac{1}{6}} .
$$

From Figure $3, A_{3} / A_{\mathrm{I}}=0.6 \mathrm{II}, T=30 \mu \mathrm{s}$, so for a capacitance of $30 \mu \mathrm{F}$ and a voltage of I $5 \mathrm{kV}$, a maximum current of $84 \mathrm{kA}$ is developed. Under these conditions, a pressure in excess of $5000 \mathrm{kPa}$ can be produced for a specimen with a $10 \mathrm{~cm} \times 2.5 \mathrm{~cm}$ cross-section. 


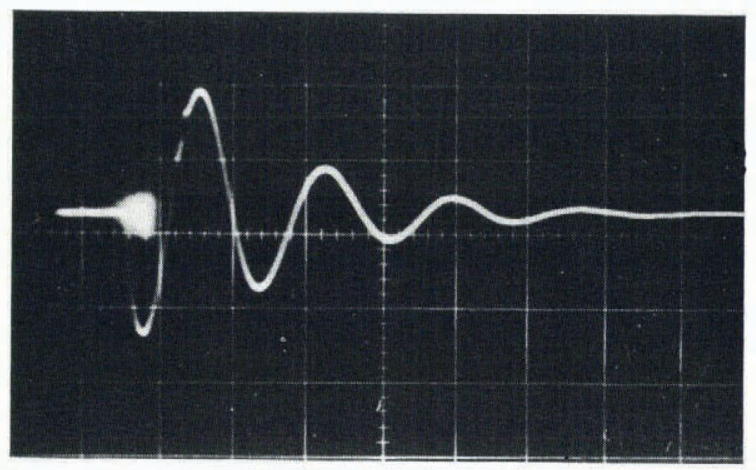

Fig. 3. Rogowski coil output, horizontal scale is $20 \mu \mathrm{s} /$ div.

Currently testing is proceeding in a very satisfactory manner on low-intensity shock waves, involving pressures ranging from $50 \mathrm{kPa}$ to $2 \mathrm{MPa}$. The stress wave in the snow specimens are monitored by a piezoresistive pressure transducer which has a flat frequency response from d.c. to $140 \mathrm{kHz}$. Figure 4 shows a typical oscilloscope output from the transducer for a test involving $260 \mathrm{~kg} / \mathrm{m}^{3}$ snow. The transducer shows a peak pressure of about $30 \mathrm{kPa}$, whereas the peak pressure generated by the stress-wave generator was $150 \mathrm{kPa}$ at a distance of $5 \mathrm{~cm}$ from the transducer. To date, the specimen cross-sectional areas as large as $15 \mathrm{~cm} \times 10 \mathrm{~cm}$ have been tested. However, larger pressures can be obtained with smaller cross-sectional areas, since peak pressure is proportional to $(i / w)^{2}$, where $i$ is the total current and $w$ the specimen width.

The test procedure is relatively simple. While the capacitor banks are uncharged, the specimen is cut and shaped and mounted on the load strips, and the pressure transducer is then positioned at the top end of the specimen. Then the capacitor bank is charged, which generally takes less than $5 \mathrm{~min}$. When the desired voltage is reached, the spark gap is pulsed, thereby completing the test. The Rogowski coil and transducer output are recorded on trace oscilloscopes. Repeatability of the system is excellent, with generator output scatter being less than $5 \%$.

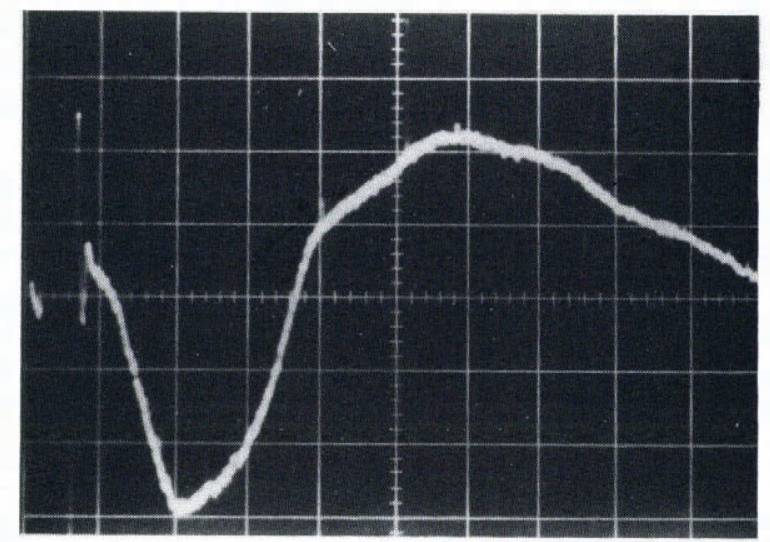

Fig. 4. Typical output from pressure transducer placed at end of test specimen. Horizontal scale is $0.2 \mathrm{~ms} /$ div, vertical scale is approximately ro $\mathrm{kPaldiv}$. 


\section{Conclusions}

The stress-wave generator described in this paper is a flexible and easily used system for studying stress-wave propagation in snow and ice. In its current configuration, the system can produce peak pressures ranging from as low as $5 \mathrm{kPa}$ to in excess of $5000 \mathrm{kPa}$. Pressures with rise times as short as $2 \mu \mathrm{s}$ can easily be achieved, and the rise time (and therefore wave frequency) may be changed by increasing the inductance of the circuit. There is also considerable flexibility with the size and shape of the test specimens which may be used, although specimens with rectangular cross-sections would be easier to work with.

\section{Acknowledgement}

The work reported here was done under U.S. Army Research Office Grant No. DRXRO-PR P-I54I3-GS.

MS. received 15 January 1980 and in revised form 20 May 1980

\section{REFERENGES}

Brown, R. L. 1980[a]. An analysis of non-steady plastic shock waves in snow. Fournal of Glaciology, Vol. 25, No. 92 , p. $279-87$.

Brown, R. L. 1980[b]. Pressure waves in snow. Journal of Glaciology, Vol. 25, No. 91, p. 99-107.

Brown, R. L. 1980 [c]. Propagation of stress waves in alpine snow. Journal of Glaciology, Vol. 26, No. 94, p. $235-43$.

Napadensky, H. 1964. Dynamic response of snow to high rates of loading. U.S. Cold Regions Research and Engineering Laboratory. Research Report 119.

Snell, R. F., and others. 1973. An electromagnetic, plane stress-wave generator, by R. F. Snell, D. C. Mackallor, and R. Guernsly. Experimental Mechanics, Vol. I3, No. I I, p. 472-79.

Wakahama, G., and Satō, A. 1977. Propagation of a plastic wave in snow. Journal of Glaciology, Vol. 19, No. 81, p. $175-83$. 